\title{
Martín BucetA: Merleau-Ponty lector de Proust: lenguaje y verdad, Buenos Aires, Sb Editorial, 2019, 285 pp.
}

\author{
Claudio Cormick \\ CONICET/IIF-SADAF \\ claudiocormick@conicet.gov.ar
}

Este primer libro del profesor argentino Martín Buceta aborda una multiplicidad de tareas. Entre ellas, y sin pretensión de exhaustividad, cabe destacar las siguientes: el análisis de la posibilidad de que el lenguaje "prosaico", como producto cristalizado de operaciones de expresión pasadas, expanda sus capacidades significativas para alcanzar fenómenos que previamente no habían sido objeto de descripción lingüística; la reconstrucción de las tesis merleaupontianas acerca de la relación entre el "mundo sensible" y el "mundo de la expresión"; la noción de "verdad" y su aplicabilidad al discurso literario, y la identificación precisa, en el texto de En busca del tiempo perdido, de instancias de lo que MerleauPonty había descrito - mucho más genéricamente- como "ideas sensibles". En rigor, el libro reserva para el final de su exposición la revelación en concreto del objeto del trabajo - una sucesión ordenada de "ideas sensibles" que localiza a lo largo de los distintos tomos de la novela de Proust-, como desenlace de una presentación paulatina de las herramientas de la filosofía merleaupontiana que, a través de la mediación del joven autor argentino, saldrán al encuentro de la ficción proustiana.

Así, en el primer capítulo ("El lenguaje"), Buceta reconstruye las reflexiones de Merleau-Ponty acerca del fenómeno del lenguaje. En los primeros dos apartados, "Ferdinand de Saussure inspirador de Maurice Merleau-Ponty" y "La 
fenomenología del lenguaje como dialéctica entre sincronía y diacronía", el autor se sirve, para este objetivo, de tres conjuntos de textos: los del propio fenomenólogo francés y sus intérpretes; el Cours de linguistique générale de Saussure, libro que ocupa para Merleau-Ponty el rol de paradigma indiscutido a la hora de analizar el lenguaje; y la interesante mediación que desarrollan, entre uno y otro autores, exponentes comparativamente menos conocidos para el público no especializado, como Sechehaye y Pos $^{1}$. Por su parte, entre el segundo apartado y el tercero (denominado "La fenomenología del lenguaje de Merleau-Ponty"), Buceta desarrolla los temas del acercamiento merleaupontiano al lenguaje que resultarán más relevantes para su cruce con la novela de Proust. En primer lugar, el texto del profesor argentino se detiene en la forma en que Merleau-Ponty adopta una perspectiva diacrónica sobre el lenguaje, desde la que se puedan estudiar sus cambios (lo que lo delimita de la estricta distinción saussuriana según la cual la lingüística debe estudiar la situación del sistema de la lengua en un momento dado, dejando de lado la dimensión individual del habla y, más en general, las transformaciones históricas) ${ }^{2}$. Pero, más específicamente, Buceta se interesa por ciertas transformaciones particulares, aquellas por medio de las cuales el lenguaje logra expandir sus recursos expresivos para lograr describir lo que antes no caía bajo su alcance. "El lenguaje", comenta el autor, "se encuentra en un estado presente (corte sincrónico) que como tal ostenta una 'fecundidad ilimitada' que da lugar a la creación de nuevas expresiones (devenir diacrónico)"33. Esta dinámica requiere, continúa Buceta, de la distinción merleaupontiana entre "lenguaje hablado" y "lenguaje hablante"; esto es, entre "el lenguaje adquirido, de que disponemos, [...] y el lenguaje que se hace en el momento de la expresión"4. Tal distinción le servirá al autor como punto de partida para estudiar el modo en que ese tipo de discurso especialmente innovador que denominamos “literatura” logra ampliar los recursos lingüísticos compartidos.

En el segundo capítulo ("Del mundo del silencio al mundo de la expresión”), Buceta aborda la manera en que Merleau-Ponty estudia, a partir de los fenómenos sensibles, las condiciones de posibilidad de que aquellos puedan ser descritos

${ }^{1}$ Cf. Buceta, Martín. Merleau-Ponty lector de Proust: lenguaje y verdad, Buenos Aires, Sb Editorial, 2019, 38-49.

${ }^{2}$ Cf. Buceta, Merleau-Ponty..., esp. 47-49

3 Buceta, Merleau-Ponty..., 57. 58.

${ }^{4}$ Merleau-Ponty, Maurice, La prose du monde, 17. Buceta comenta este pasaje en Merleau-Ponty..., 
por medio del lenguaje. Dado que uno de los objetivos que se plantea el autor es la elaboración de lo que denomina una "filosofía de lo sensible" 5 , es en el terreno de la "expresión" de estos fenómenos -antes que en otras operaciones propias de ese fenómeno multidimensional que es el lenguaje- que escoge centrarse Buceta. De particular relevancia para sus propósitos resulta el último apartado del capítulo, “Analogía y sublimación”, en que, apoyándose parcialmente en la interpretación de Stefan Kristensen, Buceta reconstruye aquí dos aspectos complementarios: el de la "analogía" entre mundo sensible y mundo de la expresión y el de la "sublimación" que - en palabras de Merleau-Ponty- "conserva y transforma el mundo percibido en el mundo hablado" 6 .

Por su parte, el tercer capítulo -el cual lleva por título “La verdad (del lenguaje literario)" - , apunta a establecer que, "así como puede instituirse un saber en el campo de la geometría o del álgebra también puede manifestarse la verdad por medio de una construcción literaria", esto es, que "puede experimentarse esa verdad a través de la poesía o la prosa"7. Aquí, aunque más no sea con el modesto propósito de resumir la exposición de Buceta, debemos dar un pequeño rodeo y señalar que las reflexiones de Merleau-Ponty sobre la noción de "verdad", a la que equipara con lo que llama "sedimentación", resultan tan oscuras que es necesario destacar que no se trata de un fallo en las tesis del autor del libro aquí comentado, sino de un defecto ya presente en la obra del fenomenólogo ${ }^{8}$. En

\footnotetext{
${ }^{5}$ Cf. Buceta, Merleau-Ponty..., “Conclusión”, esp. 265-266..

${ }^{6}$ Merleau-Ponty, Maurice, La prose du monde, 173. Buceta comenta este pasaje en Merleau-Ponty..., 88.

${ }^{7}$ Buceta, Merleau-Ponty..., 119.

8 No podemos más que citar in extenso el mismo pasaje que toma Buceta en el comienzo del tercer capítulo. En "Sobre la fenomenología del lenguaje", ponencia de 1951 publicada casi diez años después en Signos, Merleau-Ponty escribía: "Decir que hay una verdad es decir que, cuando mi reasunción encuentra el proyecto antiguo o extranjero y cuando la expresión lograda libera aquello que estaba cautivo en el ser desde siempre, en el espesor del tiempo personal e interpersonal se establece una comunicación interior por la cual nuestro presente se convierte en la verdad de todos los demás acontecimientos cognoscentes [...] En ese momento se ha fundado alguna cosa en su significación, una experiencia se ha transformado en su sentido, ha devenido verdad. La verdad es otro nombre de la sedimentación, que es a su vez la presencia de todos los presentes en el nuestro". El pasaje es sorprendente, ante todo, porque no queda claro por qué el autor francés elige conservar el término "verdad". Dicho brevemente: ¿en qué sentido una filosofía que equipara la verdad a "la sedimentación, que es a su vez la presencia de todos los presentes en el nuestro" nos está ofreciendo algo así como una teoría de "la verdad"; por qué no usar otro término - como podría ser, precisamente, "sedimentación"- para lo que se desea describir aquí? Naturalmente, Merleau-Ponty tiene derecho a estipular un significado para los términos que utilice a modo de tecnicismos, pero, cuando se trata de términos que tienen un uso habitual no solo en el lenguaje corriente sino en la filosofía, cabe esperar que si un autor utiliza tales términos lo haga con el propósito, si no de respetar a rajatabla, al menos de refinar, precisar, el sentido de esos términos, antes que el de sustituirlo por otro radicalmente diferente. Usamos el término "verdad" para intentar describir una propiedad de ciertos enunciados, o, en el caso de Buceta, para ciertas "expresiones", la cual no requiere en absoluto del fenómeno específico de "sedimentación" al que está apuntando el fenomenólogo francés.
} 
todo caso, a la hora de emprender su propio tratamiento de la obra de Proust, Buceta parece haberse independizado al menos parcialmente de la oscura caracterización de la verdad-como-sedimentación que propone Merleau-Ponty, y guiarse más bien por una definición alternativa: "entendemos por verdad", escribe Buceta, “aquella expresión del mundo vivido que lleva a cabo el lenguaje conquistador que instituye una gran prosa, es decir, aquella literatura que logra expresar el estar-en-el-mundo del cuerpo propio" 9 . En efecto, de acuerdo al autor argentino, cabe considerar que la palabra literaria "recoge y sublima la experiencia que comunica, que es, al mismo tiempo, la que la hace comprensible"; de esta manera, continúa, lo que Merleau-Ponty llama "gran prosa" logra "Ilevar a la expresión propia de su sentido al mundo vivido, decir la verdad"10.

En el capítulo 4, "Las ideas sensibles", busca echar luz sobre esta complicada noción merleaupontiana (presentada ante todo en Le visible et l'invisible, obra del autor francés reducida en buena medida, como sabemos, a notas de trabajo) asimilando tales ideas a una especie de lo que Merleau-Ponty describió como “institución": ellas, comenta Buceta, "no son ideas puras como podrían serlo las ideas platónicas, son ideas que funcionan como niveles que se establecen al contacto con lo sensible abriendo una dimensión que jamás podrá cerrarse y en relación con la cual una serie de acontecimientos será comprendida"11. En efecto, en la apropiación hecha por Merleau-Ponty del concepto husserliano de Stiftung, se trata de explicitar cómo ciertos acontecimientos que brindan inteligibilidad a otros posteriores, que se vuelven el término de comparación para comprender estos últimos, se encuentran con ellos en una "relación interna", diferente de la mera superposición ${ }^{12}$.

El capítulo 5, “En busca de la verdad: Las ideas sensibles en A la busca del tiempo perdido" está dedicado, como lo anticipa su título, a rastrear las distintas "ideas sensibles" que se presentarían en la novela de Proust. Las "ideas" en cuestión son tanto de fenómenos singulares como de generalidades ("la belleza", "la muerte"). Así, Buceta aborda sucesivamente (1) la “idea sensible articulada en palabras que constituiría la esencia de los campanarios"13 de Martinville-le-Sec

9 Ibid., 248, n.

10 l bíd., 120.

${ }^{11}$ Buceta, Merleau-Ponty..., 146.

${ }^{12}$ Cf. Maurice Merleau-Ponty, L'institution dans I'histoire personnelle et publique, Paris, Belin, 2003, pp. 43-92 (La institución [...], p. 67).

${ }^{13}$ Buceta, Merleau-Ponty..., 182. 
descritos por Proust en el primer tomo de la novela; (2) la "idea [...] del amor"14 descrita a partir de una pieza musical; (3) la "aparición sensible de la idea de Belleza"15, en el segundo tomo, À l'ombre des jeunes filles en fleur; (4) la "idea sensible [...] de la pureza de la niña-mujer"16, que el autor encuentra en el pasaje de la novela que describe el primer encuentro amoroso entre el joven narrador y Albertine; (5) la "presentación sensible de la idea de la muerte"17, que aparece en la historia a propósito del deceso de la abuela del narrador; (6) la "presentación de la idea de la seducción"18, que Buceta detecta a partir de la descripción proustiana de un episodio entre dos hombres; (7) la "idea de la inaccesibilidad del otro, de la imposibilidad de conocimiento pleno del otro"19, que figura en la trama en el marco de las dudas que aquejan al narrador acerca de la vida pasada de Albertine; (8) la "idea sensible del sufrimiento provocado por el abandono"20, que el autor del libro identifica sobre la base de la "huida" de Albertine, y de la que encuentra expresión también en un poema de Borges; (9) la "idea [...] del hastío del placer"21, en Le temps retrouvé, a propósito de la decadencia desenfrenada del barón de Charlus con posterioridad a una separación amorosa traumática, y, finalmente, (10) la "idea sensible del Tiempo como artista de la destrucción"22, en ocasión de las transformaciones ocurridas por el paso de los años en varios de los personajes de la novela, y de las que se percata el narrador en ocasión de un baile de máscaras.

De esta manera, Buceta ofrece un acercamiento "laborioso" al texto de Proust, con el nivel de detalle suficiente para cumplir con dos propósitos: ir más allá de las meras indicaciones generales sobre la obra, y ofrecer sus tesis también al lector no previamente familiarizado con el muy extenso texto de À la recherche du temps perdu. Este último objetivo, por otra parte, es reforzado en el libro por la presencia de un apartado final, titulado simplemente "A la busca del tiempo perdido" que resume la obra proustiana, en primer lugar a partir del tratamiento de sus ejes temáticos principales $\mathrm{y}$, a continuación, en la forma de un resumen

\footnotetext{
14 I bíd. , 186.

15 I bíd., 189. Cf. también 188, 190 y 192 para esta misma "idea sensible".

16 I bíd. , 196.

17 I bíd., 199. Cf también 196 para otra formulación sobre esta "idea".

18 I bíd., 209. Cf también 207 y 208 para otras formulaciones al respecto.

19 Ibíd., 214. Cf también 220.

20 I bíd., 221.

21 I bíd., 227.

22 I bíd., 238.
} 
ordenado de la trama tal como ella se desarrolla en cada uno de los siete tomos ${ }^{23}$. El aspecto del libro de Buceta que resulta comparativamente menos convincente, sin embargo - pero que seguramente, habida cuenta de la continuidad de las investigaciones del autor, será objeto de un tratamiento más preciso en sus futuros trabajos- es el que se condensa en esquemáticas formulaciones que, siguiendo pasajes igualmente esquemáticos de Merleau-Ponty, creen identificar "la similitud que existe entre filosofía y literatura en tanto que ambas tienen una tarea común y exclusiva: decir el mundo"24. Buceta nos invita de esta manera a dejar completamente de lado la dimensión argumentativa de la filosofía e incluso, lo cual no deja de ser irónico, la de la propia filosofía merleaupontiana, dimensión esta que claramente no es asimilable al trabajo del lenguaje literario. El autor del texto se apoya en frases del filósofo francés como aquella de la Phénoménologie de la perception en que se afirma que "la fenomenología es laboriosa como las obras de Balzac, Proust, Valéry o Cézanne"25, pero no se detiene a analizar si lo que Merleau-Ponty dice hacer como fenomenólogo efectivamente equivale a lo que hace. Un análisis que se centre en el segundo aspecto y no en el primero encontrará a lo largo de los textos merleaupontianos no tanto "descripciones del mundo" sino extensas argumentaciones, mejores o peores, que buscan sostener las propias posiciones y discutir las tesis de adversarios que introduce con categorías -frecuentemente solapadas entre sí- como "intelectualismo", "empirismo", "psicología clásica”, "pensamiento objetivo", etcétera (característica esta del autor francés que probablemente distinga radicalmente textos como la Phénoménologie o incluso Le visible et l'invisible con respecto al estilo, mucho más "descriptivo", del Husserl de I deas I o el Heidegger de Ser y tiempo). Como fuere, el público interesado en las relaciones entre filosofía y literatura encontrará en el texto de Buceta un estimulante material de trabajo, incluso si no toma a valor nominal cierto intento de pronunciarse globalmente acerca de la tarea filosófica.

23 I bíd., 251-264.

24 I bíd., 265.

${ }_{25}$ Merleau-Ponty, M., Phénoménologie de la perception, p. XVI. Buceta comenta este pasaje en Merleau-Ponty..., p. 25. 